\title{
Factors leading to poor physical health in people with psychosis
}

\author{
CHIARA SAMELE
}

\section{INTRODUCTION}

Poor physical health in people with psychosis is a growing area of concern, not least because this group is particularly vulnerable to physical health problems but because of a serious neglect in preventing, detecting and managing these problems. The following editorial discusses the some of main factors contributing to poor physical health in people with severe mental illness, including detection, management and prevention issues, the extent of the problem and some recommendations for improving physical health care.

\section{Mortality from natural causes}

An increasing number of studies have found higher rates of mortality in people with schizophrenia due to natural causes (Ruschena et al., 1998; Felker et al., 1996; Mortensen \& Juel, 1993). Such increased rates of mortality due to natural causes in people with schizophrenia highlight the failure to detect and manage physical health conditions in this group. In a meta-analysis deaths due to natural causes accounted for $59 \%$ of the excess mortality in schizophrenia (Brown, 1997). Respiratory and cardiovascular diseases are the most common causes of natural death. The standard mortality ratio (SMR) for respiratory disease was 226 (95\% CI, 209-244), although for cardiovascular disease the increase was marginal with an SMR of $110(95 \% \mathrm{CI}, 105-115)$ (Brown, 1997). However, Lawrence et al. (2003) found an SMR of 1.78 for men

Address for correspondence: Dr. C. Samele, Honorary Lecturer, c/o Division of Psychological Medicine, Po 63, Institute of Psychiatry, London SE5 8AF (United Kingdom).

E-mail: c.samele@iop.kcl.ac.uk

Declaration of Interest: none. and 0.86 for women with schizophrenia for ischaemic heart disease (Lawrence et al., 2003). Mortality from digestive diseases also presents a problem where the SMR was 185 (95\% CI, 164-208) (Brown, 1997).

Another indicator of the quality of the medical care is 'avoidable mortality'. These figures are calculated by selecting the number of avoidable causes of death considered amenable to health care (Rutstein et al., 1976). Ringbäck-Weitoft et al. (1998) conducted a follow-up study of 30,045 psychiatric in-patients born between 1912-1970 to specifically address avoidable mortality. The standardised rate ratios (SRR) for male patients with schizophrenia are 3.74 (95\% CI, 2.38-5.89) and 3.99 (95\% CI, 2.47-6.44) for females (Ringback Weitoft et al., 1998).

\section{Medical comorbidity - types and prevalence}

Lambert et al. (2003) list some of the common physical conditions found in people with psychosis. These include diabetes, hyperlipdaemia, cardiovascular disease, obesity, malignant neoplasms, HIV/AIDS, hepatitis, osteoporosis, hyperprolactinaemia, irritable bowel syndrome and helicobacter pylori infection (Lambert et al., 2003).

The prevalence of physical illness in medically screened, chronic psychiatric samples has been variously reported to be 12-53\% (Honig et al., 1989; Lyketsos et al., 2002). One of the few studies examining medical comorbidity in 102 patients with first episode psychosis found a prevalence of $17.6 \%$ (Strakowski et al., 1993). Felker et al. (1996) estimate that 35\% of psychiatric patients have undiagnosed physical disorders (Felker et $a l .$, 1996). Dickey et al. (2002) found not only were certain treated medical conditions more prevalent among people with psychosis, but they were twice as likely to be treated for two or more physical conditions (Dickey et al., 2002). Some studies have attempted to establish whether medical comorbidity exacerbates patients' psy- 
chiatric condition (Bartsch et al., 1990; Koran et al., 1989). Hall et al. (1981), for example, found $46 \%$ of psychiatric patients admitted to a research ward had undetected physical health conditions that could cause or exacerbate their mental illness (Hall et al., 1981).

Felker et al. (1996) note that although it is well known that psychiatric patients have increased risk for concurrent medical illness, defining a profile of those at high risk may also be important (Felker et al., 1996). Some variables are not always predictive, for example, gender, ethnicity, diagnosis, programme setting, and regular medical check up. The high-risk groups, however, include elderly patients, those with organic brain syndromes, patients who are substance abusers, women, and patients of lower socio-economic status.

\section{POOR DETECTION AND MANAGEMENT OF MEDICAL COMORBIDITY}

A number of reasons exist to explain the poor detection of physical health problems in people with psychosis. Some people with mental illness are unaware of any physical health problems, usually a consequence of cognitive deficits associated with their mental illness (Goldman, 1999). Often there is a reluctance to seek medical help and when it is sought people with mental illness find it difficult to describe their problems to a medical practitioner, or present with atypical medical symptoms (Bunce et al., 1982; Holmberg, 1988). People with schizophrenia have been shown to have a high tolerance for pain and subsequently are less likely to report this as a symptom (Dworkin, 1994). Another complexity concerns the effects of psychiatric illness on perceived physical health. For example, depression can lead to an increase in perceived physical symptoms and worsening of subjective health outcomes (i.e. health perception and quality of life). The temporal relationship between physical symptoms and psychiatric illness is often difficult to determine given most morbidity studies are cross-sectional, although the direction of causality may operate in both ways (Hotopf et al., 1998).

The management of medical conditions in people with mental illness is a complex and problematic issue, arising largely because of the separation of medical and psychiatric health care services (Dickey et al., 2002). Many investigators highlight the inadequate nature of physical health care for people with mental illness and the reasons for this. The stigma of mental illness is one obvious barrier preventing psychiatric patients from receiving adequate physical health care, as some physicians may be uncomfortable in working with this group (Phelan et al., 2001). Another concern is managing physical conditions where patients that have an increased prevalence in patients with psychiatric illness and where there is a general lack of treatment compliance (Brown et al., 2000). One example is diabetes, where managing this condition may be very difficult in patients with schizophrenia. Another example is asthma in people with psychosis where special follow up care is needed after asthma attacks (Levy, 1996). Mirza \& Phelan (2002) point out the challenging task of managing physical illness in people with severe mental illness, which requires skill, patience and experience as patients often present late with complications (Mirza \& Phelan, 2002).

\section{Lifestyle risk factors}

\section{Alcohol and substance abuse}

Investigations examining risk factors, such as alcohol and substance use have not always been associated with physical health problems but rather increased psychiatric symptomatology, and increased days in hospital (Menezes et al., 1996; Reiger et al., 1990). Substantial evidence exists to show that patients with schizophrenia have greater than average rates of alcohol consumption and substance use. The lifetime prevalence of alcohol abuse or dependence affected $33 \%$ of people diagnosed with schizophrenia, and was 3.3 times higher than the general population in the Epidemiological Catchment Area study (Reiger et al., 1990). Drake et al. (1989) found $45 \%$ of 115 discharged patients with schizophrenia used alcohol and 22\% had heavier use patterns (Drake $e t$ al., 1989). Similarly, higher percentages of patients, $34 \%$ used illicit drugs, many of whom abused more than one drug. The characteristics of patients using alcohol was associated with younger age, being male, illicit drug use, medication non-compliance, lack of psychosocial supports, increased symptomatology, chronic medical problems and higher rates of rehospitalisation (Drake et al., 1989).

One study, however, examines whether comorbid substance misuse increases the prevalence of particular types of medical conditions over and above the effect of severe mental illness alone (Dickey et al., 2002). Dickey et al. (2002) found people with psychosis and comorbid substance misuse had the highest adjusted odds ratios for five of the eight medical conditions examined: heart disease, asthma, gastrointestinal disorders, skin infections and acute respiratory disorders, when compared to those with psychosis but without substance misuse and those without psychosis but with a substance use problem. 


\section{Smoking}

The prevalence of smoking is markedly high among patients with schizophrenia compared to the general population. Estimates have been as high as $70 \%$ or more (de Leon, 1996). In assessing levels of smoking in psychiatric outpatients, Hughes et al. (1986) found it was particularly prevalent among patients with schizophrenia compared to those with mania ( $88 \%$ vs $70 \%$ respectively), even when controlling for age, sex, marital status, socio-economic status, alcohol or coffee use and institutionalisation. The prevalence of smoking also varies with illness severity (i.e. comparing patients previously hospitalised with those who were not) $(62 \%$ vs. $38 \%, p<0.01)$ (Hughes et al., 1986). The high prevalence of smoking among psychiatric patients has not always resulted in increased rates of smoking related illnesses, such as lung cancer (Tsuang et al., 1983). Respiratory symptoms (i.e. cough, shortness of breath and wheezing) are significantly greater in community psychiatric patients compared to the general population (Kendrick, 1996). However, Lichtermann et al. (2001) show that people with schizophrenia are at increased risk of lung cancer (Standardised incidence ratio: SIR, 2.17, 1.7-2.6) and, in particular pharyngeal cancer (SIR, 2.60, 1.2-4.8).

Smoking also affects the pharmacological treatment of schizophrenia by modulating neuroleptic side effects and increasing neuroleptic metabolism. Smokers with schizophrenia often require higher doses of neuroleptics than non-smokers (Goff et al., 1992; Ziedonis et al., 1994). However, there is some evidence to show when patients are treated with atypical antipsychotics, such as clozapine, the drive to smoke becomes significantly less (McEnvoy et al., 1999).

The chronological relationship between smoking and schizophrenia may be an important factor in understanding increased smoking levels in psychiatric patients. As de Leon (1996) stresses, if the onset of smoking began prior to the onset of schizophrenia then familial or genetic factors may be relevant (de Leon, 1996). On the other hand, if patients start smoking after the onset of schizophrenia it may be important to explore the influence of other patients and the treatment environment (de Leon, 1996).

\section{Antipsychotic medication}

Treatment for schizophrenia has been associated with a number of adverse side effects, including involuntary movement disorders, such as akathisia, parkinsonism, and the most common, tardive dyskinisia (TD), particularly with the use of old antipsychotic medication (Jeste et al., 1996). New antipsychotics (i.e. clozapine and risperidone) are more commonly used in newly diagnosed patients with psychosis. Despite the low propensity of new antipsychotics towards extrapyramidal side effects other adverse effects associated with them include excessive weight gain, endocrine disturbances, hypotension and seizures (Lader, 1999).

Medical conditions attributed to the use of typical and atypical antipsychotic medication include diabetes (Koro et al., 2002); hyperlipidaemia (Meyer, 2002); cardiovascular disease (specifically hypertension and cardiac arrhythmias) (Davidson, 2002); obesity in which $40 \%$ $62 \%$ of people with schizophrenia are obese or overweight (Taylor \& McAskill, 2000); osteoporosis (Halbreich \& Palter, 1996); and, hyperprolactinaemia (Wieck \& Haddad, 2002).

\section{Diet and exercise}

Very few studies have investigated lifestyles of patients with schizophrenia, despite anecdotal reports of their poor diet and inadequate exercise (Brown et al., 1999). Brown et al. (1999) assessed lifestyle of patients with schizophrenia by measuring diet, obesity, exercise, substance use and cigarette smoking. Compared to the reference population patients in the study had a diet high in dietary fat and low in fibre (Brown et al., 1999). The majority of the 102 patients reported only light or no exercise in the previous week, (males: $45 \%$ and $36 \%$ respectively; females: $57 \%$ and $32 \%$ respectively). McCreadie et al. (1998) in a dietary study in patients with schizophrenia found they had low antioxidant intake and low ratios of serum vitamin $\mathrm{E}$ concentration to cholesterol concentration, also a risk factor for cardiovascular disease (McCreadie et al., 1998).

\section{A TIME FOR CHANGE}

\section{Improving physical health care for the severely mentally ill}

Regular physical health checks are seldom systematically performed, and monitoring of physical health and health education by community mental health staff is often unsatisfactory (Beecroft et al., 2001). There has been some debate in the literature as to who should monitor the physical health of people with mental illness. Some argue the patient's General Practitioner (GP) appears to be the person most suited to be responsible for his/her physical health (Jeste et al., 1996; Honig et al., 
1992). Beecroft et al. (2001) stress the need to introduce a system of regular health check ups for those with severe mental illness together with more proactive follow-ups by GPs (Beecroft et al., 2001). However, as Phelan et al. (2001) point out most patients with severe mental illness contact primary care services, but it is clear that this does not ensure access to good physical health care (Phelan et al., 2001), despite GPs being better equipped to do so.

Mental health services, however, cannot avoid providing an adequate minimum of standard routine assessments to identify and monitor physical health problems in people with severe mental illness. Many contend that improving the physical health of people with severe mental illness starts with using a standard checklist to routinely collect core information concerning physical health and mental health professionals should be adequately equipped to perform basic physical medicine tasks and maintain access to specialist health care where necessary (Bunce et al., 1982; Karasu et al., 1980; Seymour, 2003). Lambert et al. (2003) argue that members of community-based multidisciplinary teams. should receive support and training for managing physical comorbidity, particularly in view of the day-to-day role they play in managing and influencing patients' mental health (Lambert et al., 2003).

Some programmes have been introduced to improve physical health. One example includes a Psychiatric/Medical Comorbidity Program in North America providing inpatient consultation and treatment for people with both mental illness and physical health problems. Here the service assesses patients to clarify psychological problems from the effects of their mental illness and adapt medical treatment in view of their psychological circumstances (see http://info.med.yale.edu/yfp/referral/psyc/psy.html). Current policy in the UK acknowledges the importance of meeting the physical health needs of people with mental illness. The National Service Framework for Mental Health (1999) includes national standards for mental health services, which incorporates the improvement of physical health care. This aims to reduce stigma and discrimination within health care services, but also sets the task of delivering physical health care to the mentally ill through primary care services. For the reasons described above this policy may well fall short of what is needed.

\section{The need for prevention strategies}

In the debate on physical health in the severely mentally ill the most seriously neglected part concerns prevention programmes to target the unhealthy lifestyles factors that lead to poor physical health. Here the research literature is especially scant. Dietary and exercise programmes should be an essential part of what mental health services provide. Tobacco smoking is of particular concern, but targeting this, however, presents a multitude of dilemmas. Promoting physical health can be difficult in view of the acceptance of smoking on many psychiatric in-patient wards and the reluctance/difficulties linked to prohibiting smoking on psychiatric wards (Gralnick, 1990). Nevertheless, some studies have highlighted the willingness of people with severe mental illness to give up smoking (Addington et al., 1997), and there is certainly a need for appropriate smoking cessation programmes for people with schizophrenia offering a flexible approach (el-Guebaly et al., 2002; McChargue et al., 2002). Indeed a small number of smoking cessation studies for people with schizophrenia have shown some degree of success (George et al., 2000; 2002) and is certainly worth pursuing.

There remains a fare way to go before factors leading to poor physical health in people with psychosis change for the better. Fortunately these are achievable goals.

\section{REFERENCES}

Addington J., el-Guebaly N., Addington D. \& Hodgins, D. (1997). Readiness to stop smoking in schizophrenia. Canadian Journal of Psychiatry 42, 49-52.

Bartsch D.A., Shern D.L., Feinberg L.E., Fuller B. \& Willett A. (1990). Screening CMHC outpatients for physical illness. Hospital and Community Psychiatry 41, 786-790.

Beecroft N., Becker T., Griffiths G., Leese M., Slade M. \& Thornicroft G. (2001). Physical health care for people with severe mental illness: The role of the general practitioner (GP). Journal of Mental Health 10, 53-61.

Brown S. (1997). Excess mortality of schizophrenia. British Journal of Psychiatry 171, 502-508.

Brown S., Birtwhistle J. \& Roe L. (1999). The unhealthy lifestyle of people with schizophrenia. Psychological Medicine 29, 697-701.

Brown S., Inskip H. \& Barraclough B. $(2000)$. Causes of the excess mortality of schizophrenia. British Journal of Psychiatry 177, 212217.

Bunce D.F. 2nd, Jones L.R., Badger L. \& Jones S.E. (1982) Medical illness in psychiatric patients: barriers to diagnosis and treatment. Southern Medical Joumal 75, 941-944.

Davidson M. (2002). Risk of cardiovascular disease and sudden death in schizophrenia. Journal of Clinical Psychiatry 63, 5-11.

de Leon J. (1996). Smoking and vulnerability for schizophrenia. Schizophrenia Bulletin 22, 405-409.

Dickey B., Normand S.L.T., Weiss R.D., Drake R. \& Azeni H. (2002). Medical morbidity, mental illness and sustance use disorders. Psychiatric Services 53, 861-867.

Drake R., Osher F. \& Wallach M. (1989). Alcohol use and abuse in schizophrenia. A prospective community study. Journal of Nervous and Mental Disease 177, 408-414.

Dworkin R. (1994). Pain insensitivity in schizphrenia: A neglected phenomenon and some implications. Schizophrenia Bulletin 20, 235 248.

el-Guebaly N., Cathcart J., Currie S., Brown D. \& Gloster S. (2002). Smoking cessation approaches for persons with mental illness or addictive disorders. Psychiatric Services 53, 1166-1170.

Felker B., Yazel J.J. \& Short D. (1996). Mortality and medical comor- 
bidity among psychiatric patients: A review. Psychiatric Services $47,1356-1363$.

George T.P., Ziedoni D., Feingold A., Pepper W., Satterburg C., Winkel J., Rounsaville B.J. \& Kosten T.R. (2000). Nicotine transdermal patch and atypical antipsychotic medications for smoking cessation in schizophrenia. American Journal of Psychiatry 157, 1835-1842.

George T.P., Vessicchio J.C., Termine A., Bregartner T. A., Feingold A., Rounsaville B. J. \& Kosten, T.R. (2002). A placebo controlled trial of bupropion for smoking cessation in schizophrenia. Biological Psychiatry 52, 53-61.

Goff D., Henderson D. \& Amico E. (1992). Cigarette smoking in schizophrenia: relationship to psychopathology and medication side effects. American Journal of Psychiatry 149, 1189-1194.

Goldman L. (1999). Medical illness in patients with schizophrenia. Journal of Clinical Psychiatry, Suppl. 21, vol. 60, pp.10-15.

Gralnick A. (1990). Nicotine addiction in the psychiatric hospital: Final report. Psychiatric Journal of the University of Ottawa 15, 165-168.

Halbreich U. \& Palter S. (1996). Accelerated osteoporosis in psychiatric patients: Possible pathophysiological processes. Schizophrenia Bulletin 22, 447-454.

Hall R., Gardener E., Popkin M., Lecann A.F. \& Stickney S.K. (1981). Unrecognised physical illness prompting psychiatric admission: a prospective study. American Journal of Psychiatry 138, 629-635.

Holmberg S. (1988). Physical health problems of the psychiatric client. Journal of Psychosocial Nursing and Mental Health Services 26, 35-39.

Honig A., Pop P., Tan E., Philipsen H. \& Romme, M. (1989). Physical illness in chronic psychiatric patients from a community psychiatric unit. The implications for daily practice. British Journal of Psychiatry 155, 58-64.

Honig A., Pop P., de Kemp E., Philipsen H. \& Romme, M. (1992). Physical illness in chronic psychiatric patients from a community psychiatric unit revisited. A three-year follow-up study. British Journal of Psychiatry 161, 80-83.

Hotopf M., Mayou R., Wadsworth M. \& Wessely S. (1998). Temporal relationships between physical symptoms and psychiatric disorder. British Journal of Psychiatry 173, 255-261.

Hughes J., Hatsukami D., Mitchell J. \& Dahlgren L. (1986). Prevalence of smoking among psychiatric outpatients. American Journal of Psychiatry 143, 993-997.

Jeste D., Gladsjo J., Lindamer L. \& Lacro J. (1996). Medical comorbidity in schizophrenia. Schizophrenia Bulletin 22, 413-427.

Karasu T., Waltzman S., Lindermayer J. \& Buckley P. (1980). The medical care of patients with psychiatric illness. Hospital and Community Psychiatry 31, 463-472.

Kendrick T. (1996). Cardiovascular and respiratory risk factors and symptoms among General Practice patients with long-term mental illness. British Journal of Psychiatry 169, 733-739.

Koran L., Sox H., Marton K., Moltzen S., Sox C., Kraemer H., Imai K., Kelsey T.G., Rose T.G. Jr, Levin L.C., et al. (1989). Medical evaluation of psychiatric patients. I. Results in a state mental health system. Archives of General Psychiatry 46, 733-740.

Koro C.E., Fedder D.O., L'Italien G.J., Weiss S.S., Magder L.S., Kreyenbuhl J., Revicki D.A. \& Buchanan R.W. (2002). Assessment of independent effect of olanzapine and risperidone on risk of diabetes among patients with schizophrenia: population based nested case-control study. British Medical Journal 325, 243-247.

Lader M. (1999). Some adverse effects of antipsychotics: Prevention and treatment. Journal of Clinical Psychiatry 60, 18-21.

Lambert T.J.R., Velakoulis D. \& Pantelis C. (2003). Medical comorbidity in schizophrenia. Medical Journal of Australia 178, Suppl. 5, 567-570.

Lawrence D., Holman C., Jablensky A. \& Hobbs M. (2003). Death rate from ischaemic heart disease in Western Australian psychiatric patients 1980-1998. British Journal of Psychiatry 182, 31-36.
Levy M. (1996). Asthmatic patients with psychosis need special care. British Medical Journal 312, 82-83.

Lichtermann D., Ekelund J., Pukkala E., Tanskanen A. \& Lonnqvist J. (2001). Incidence of cancer among persons with schizophrenia and their relatives. Archives of General Psychiatry 58, 573-578.

Lyketsos C., Dunn G., Kaminsky M. \& Breakey W. (2002). Medical comorbidity in psychiatric inpatients. Relation to clinical outcomes and hospital length of stay. Psychosomatics 43, 24-30.

McChargue D., Gulliver S. \& Hitsman B. (2002). Would smokers with schizophrenia benefit from a more flexible approach to smoking treatment? Addiction 97, 785-793.

McCreadie R., MacDonald E., Blacklock C., Tilah-Singh D., Wiles D. \& Halliday J. (1998). Dietary intake of schizophrenia patients in Nithsdale, Scotland: Case-control study. British Medical Journal, 784-785.

McEnvoy J., Freudenreich O. \& Wilson W. (1999). Smoking and therapeutic response to clozapine in patients with schizophrenia. Biological Psychiatry 46, 125-129.

Menezes P., Johnson S., Thornicroft G., Marshall J., Prosser. D., Bebbington P. \& Kuipers E. (1996). Drug and alcohol problems among individuals with severe mental illnesses in South London. British Journal of Psychiatry 168, 612-619.

Meyer J. M. (2002). A retrospective comparison of weight, lipid, and glucose changes between risperidone- and olanzapine-treated inpatients: Metabolic outcomes after 1 year. Journal of Clinical Psychiatry 63, 425-433.

Mirza I. \& Phelan M. (2002). Managing physical illness in people with severe mental illness. Hospital Medicine 63, 535-539.

Mortensen P. \& Juel K. (1993). Mortality and causes of death in first admitted schizophrenic patients. British Journal of Psychiatry 163, 183-189.

Phelan M., Stradins L. \& Morrison S. (2001). Physical health of people with severe mental illness. British Medical Journal 322, 443-444.

Reiger D., Farmer M., Rae D., Locke B., Keith S., Judd L. \& Goodwin F. (1990). Comorbididty of mental disorders with alcohol and other drug abuse. Journal of the American Medical Association 264, 2511-2518.

Ringback Weitoft G., Gullberg A. \& Rosen M. (1998). Avoidable mortality among psychiatric patients. Social Psychiatry and Psychiatric Epidemiology 33, 430-437.

Ruschena D., Mullen P., Burgess P., Cordner S., Barry-Walsh J., Drummer O., Palmer S., Browne C. \& Wallace C. (1998). Sudden death in psychiatric patients. British Journal of Psychiatry 172, 331336.

Rutstein D., Berenberg W., Chalmers T,, Child C.G. 3rd, Fishman A.P. \& Perrin E.B. (1976). Measuring the quality of medical care. A clinical method. New England Journal of Medicine 294, 582-588.

Seymour L. (2003). Not All in the Mind: the Physical Health of Mental Health Service Users. Mentality: London.

Strakowski S., Tohen M., Stoll A., Faedda G., Mayer P., Kolbrener M. \& Goodwin D. (1993). Comorbidity in psychosis at first hospitalization. American Journal of Psychiatry, 752-757.

Taylor D. \& McAskill R. (2000). Aytypical antipsychotics and weight gain - a systematic review. Acta Psychiatrica Scandinavica 101, 416-432.

Tsuang M., Perkins K. \& Simpson J. (1983). Physical diseases in schizophrenia and affective disorder. Journal of Clinical Psychiatry 44 , 42-46.

Wieck A. \& Haddad P. (2002). Hyperprolactinaemia caused by antipsychotic drugs. British Medical Journal 324, 250-252.

Ziedonis D., Kosten T. R., Glazier W. \& Frances R. (1994). Nicotine dependence and schizophrenia. Hospital and Community Psychiatry $45,204-206$ 